\title{
Impact of anemia on short-term survival in severe COPD exacerbations: a cohort study
}

This article was published in the following Dove Press journal:

International Journal of COPD

I August 2016

Number of times this article has been viewed

\author{
Begum Ergan' \\ Recai Ergün ${ }^{2}$ \\ 'Department of Pulmonary and \\ Critical Care, Faculty of Medicine, \\ Dokuz Eylül University, Izmir, Turkey; \\ ${ }^{2}$ Medical Intensive Care Unit, Dıșkapı \\ Yıldırım Beyazıt Education and \\ Research Hospital, Ankara, Turkey
}

Video abstract

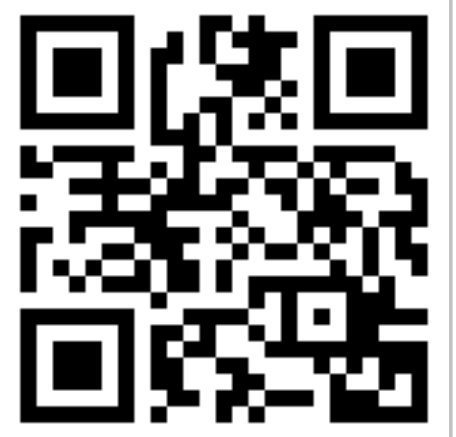

Point your SmartPhone at the code above. If you have a QR code reader the video abstract will appear. Or use:

http://youtu.be/oVAe-gOXUVA
Correspondence: Begum Ergan Department of Pulmonary and Critical Care, Faculty of Medicine, Dokuz Eylül University, Mithatpasa Cd, No I606, Inciraltı, 35340, Izmir, Turkey Tel +905326327686 Email begumergan@hotmail.com
Purpose: Anemia is reported to be an independent predictor of hospitalizations and survival in COPD. However, little is known of its impact on short-term survival during severe COPD exacerbations. The primary objective of this study was to determine whether the presence of anemia increases the risk of death in acute respiratory failure due to severe COPD exacerbations.

Patients and methods: Consecutive patients with COPD exacerbation who were admitted to the intensive care unit with the diagnosis of acute respiratory failure and required either invasive or noninvasive ventilation (NIV) were analyzed.

Results: A total of 106 patients (78.3\% male; median age 71 years) were included in the study; of them $22(20.8 \%)$ needed invasive ventilation immediately and $84(79.2 \%)$ were treated with NIV. NIV failure was observed in 38 patients. Anemia was present in $50 \%$ of patients, and 39 patients (36.8\%) died during hospital stay. When compared to nonanemic patients, hospital mortality was significantly higher in the anemic group ( $20.8 \%$ vs $52.8 \%$, respectively; $P=0.001)$. Stepwise multivariate logistic regression analysis showed that presence of anemia and NIV failure were independent predictors of hospital mortality with odds ratios ( $95 \%$ confidence interval) of 3.99 ([1.39-11.40]; $P=0.010)$ and 2.56 ([1.60-4.09]; $P<0.001)$, respectively. Anemia was not associated with long-term survival in this cohort.

Conclusion: Anemia may be a risk factor for hospital death in severe COPD exacerbations requiring mechanical ventilatory support.

Keywords: chronic obstructive pulmonary disease, exacerbation, acute respiratory failure, mortality, anemia, noninvasive ventilation

\section{Introduction}

COPD is a major cause of health burden throughout the world. ${ }^{1}$ COPD often coexists with comorbidities such as cardiovascular diseases, osteoporosis, skeletal muscle dysfunction, depression, and anemia. ${ }^{2,3}$ The common ground for most of these extrapulmonary problems is the ongoing severe inflammation. Comorbidities have an influence on potentiating the overall morbidity of COPD, leading to increased hospitalizations, health care costs, and eventually death.

Anemia is a well-known comorbidity of COPD with a prevalence ranging from 12.3 to $23 \% .^{3-5}$ Previous studies also showed that the prevalence is much higher during exacerbations. ${ }^{6-8}$ Anemia in COPD is directly associated with adverse clinical outcomes, including death. Hemoglobin levels correlated with dyspnea scores, exercise capacity, and several inflammatory markers in COPD. ${ }^{9-12}$ Anemia has also been shown as an independent predictor of recurrent hospitalizations and survival in COPD patients with chronic respiratory failure. ${ }^{13,14}$

It has been suggested that low hemoglobin levels may impair gas exchange and cardiorespiratory interaction in COPD patients. ${ }^{4,11}$ This effect is expected to be more prominent in severe COPD exacerbations presenting with acute respiratory failure 
in which the oxygen demand is supposed to be high due to increased respiratory workload. In this study, we sought to identify whether anemia is related with higher in-hospital deaths in severe COPD exacerbations. Secondary end points were to evaluate the impact of anemia on noninvasive ventilation (NIV) failure and long-term survival.

\section{Patients and methods}

\section{Study population}

This cohort study was conducted in a 14-bed medical intensive care unit (ICU) of a tertiary reference hospital. The ethics committee of Dışkapı Yıldırım Beyazıt Education and Research Hospital approved the study (approval number: 10/29). Written informed consent was obtained to be included in this study from either the patient him/herself or patient's relatives. All consecutive COPD exacerbation patients who developed acute respiratory failure were evaluated between April 2012 and September 2015. Diagnosis of COPD was confirmed, according to the Global initiative for chronic Obstructive Lung Disease (GOLD), from medical records, and if available pulmonary function tests (PFTs) within the previous year. ${ }^{1}$ In patients for whom PFTs were unavailable, COPD diagnosis was confirmed with GOLD clinical criteria (age $>40$ years, $>10$ pack-year smoking or biomass history).

The exclusion criteria were as follows: 1) suspected alternative/additional cause for respiratory failure such as pneumonia, pulmonary embolism, cardiogenic pulmonary edema, severe sepsis, acute respiratory distress syndrome, 2) presence of active bleeding, 3) presence of a disease/treatment possibly associated with bone marrow suppression (renal failure with glomerular filtration rate $<30 \mathrm{~mL} / \mathrm{min} / 1.73 \mathrm{~m}^{2}$, malignancy, hematologic disorders), and 4) recent operation or transfusion history.

Demographic characteristics (age, sex, smoking history), recent PFTs - if available, presence of comorbidities, use of long-term oxygen therapy and domiciliary NIV, duration of hospital stay prior to ICU admission, severity scores of Acute Physiology and Chronic Health Evaluation (APACHE) II and Glasgow Coma Scale (GCS) were recorded.

Laboratory data for admission arterial blood gas analysis, complete blood cell count, and serum CRP were collected. Anemia was defined as hemoglobin levels $<12 \mathrm{gm} / \mathrm{dL}$ for female patients and $<13 \mathrm{gm} / \mathrm{dL}$ for male patients according to the World Health Organization (WHO) anemia definition. ${ }^{15}$

\section{Data collection for mechanical ventilation and follow-up}

All patients had acute respiratory failure due to an exacerbation and were supported by either invasive (mechanical ventilation with endotracheal intubation) ventilation or NIV according to the degree of respiratory failure and the patient's clinical condition. NIV was performed by experienced ICU staff using pressure support mode through an oronasal mask. NIV failure was defined as requiring endotracheal intubation at any time.

Initial mechanical ventilation support type, failure in NIV, total duration of mechanical ventilation support, the lengths of ICU and hospital stays, and ICU and hospital mortality were recorded. For survivors, mortality was evaluated from the national death database system on January 31, 2016.

\section{Statistical analysis}

The primary outcome of the study was whether the presence of anemia on admission is a risk factor for hospital mortality in severe COPD exacerbations. Secondary outcomes were the effect of anemia on NIV failure and long-term survival. The sample size $(n=106)$ was calculated assuming an alpha error of $5 \%$ to reject the null hypothesis with a statistical power of $80 \%$ and anticipating $5 \%$ dropout rate. ${ }^{16}$

All categorical variables are expressed as numbers and percentages, and continuous variables were expressed as median and interquartile range. Categorical variables between groups were compared with chi-square or Fisher's exact test, continuous variables were compared with Mann-Whitney $U$-test. The independent effect of anemia on hospital mortality was assessed with stepwise multivariate logistic regression analysis. To build the model, a purposeful selection method was used to select a subset of covariates that were considered to be clinically important, adjusting for confounders and statistical significance. An adjusted odds ratio (OR) and a 95\% confidence interval (CI) were reported for each independent factor. A two-tailed $P$-value of $<0.05$ was considered statistically significant. Statistical analysis was performed with SPSS (Statistical Package for the Social Sciences Version 20; IBM Corporation, Armonk, NY, USA) program.

\section{Results}

Study flowchart is presented in Figure 1. A total of 124 patients were screened and 106 patients (78.3\% male; median age 71 years) were included in the study. Patient characteristics are shown in Table 1. PFTs were available in 62 patients; the median (interquartile range) forced expiratory volume in 1 second $\left(\mathrm{FEV}_{1}\right) \%$ predicted was $31.4 \%(20.5 \%-40.2 \%)$. Thirty-seven (34.9\%) patients were using long-term oxygen therapy and $15(14.2 \%)$ patients were using NIV at home. Hypertension and coronary artery disease were the most common comorbidities. Twelve patients had a respiratory arrest event before ICU admission. On ICU admission, the 


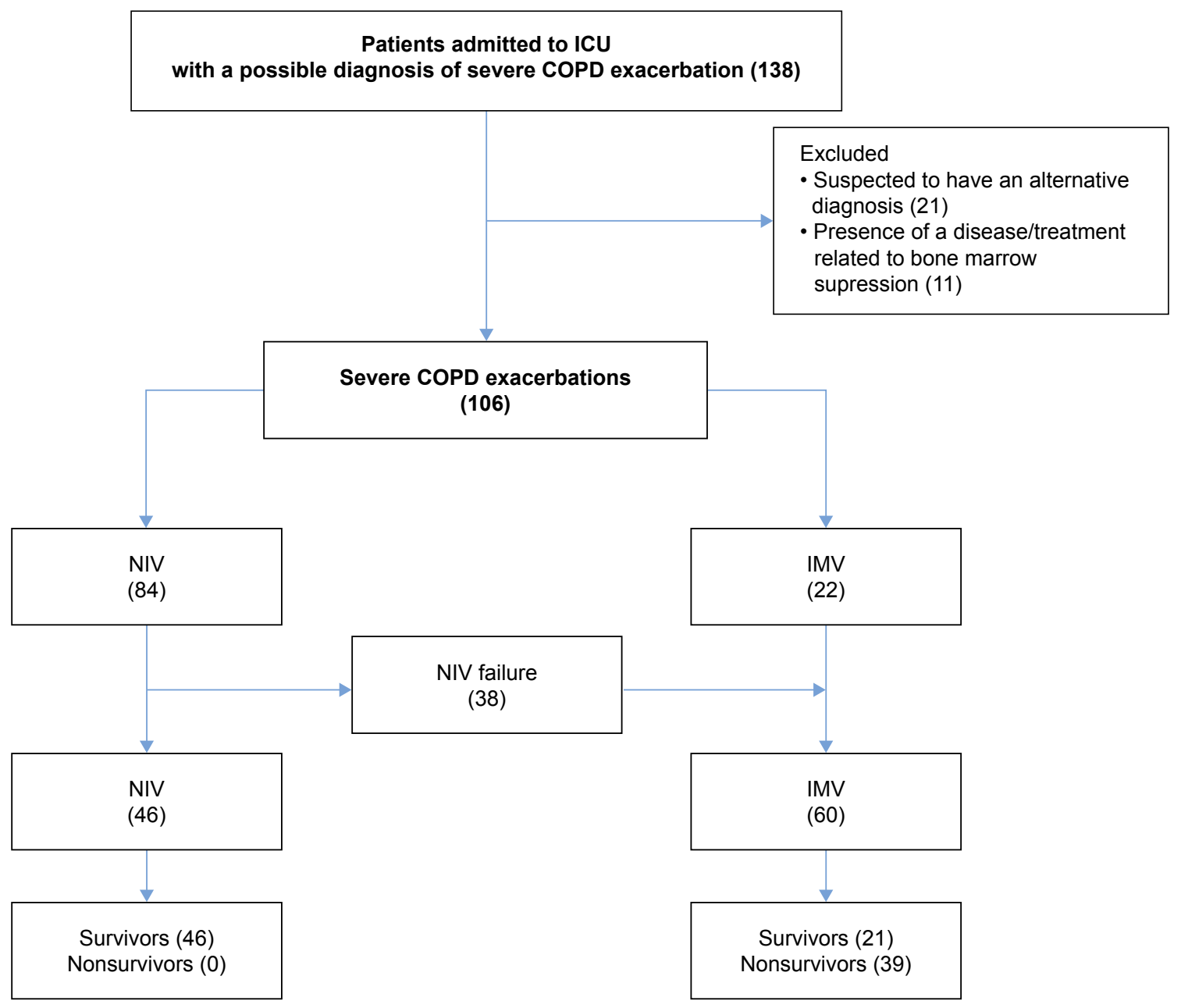

Figure I Study flowchart and hospital outcomes of the study population.

Abbreviations: ICU, intensive care unit; IMV, invasive mechanical ventilation; NIV, noninvasive ventilation.

median APACHE II and GCS scores were $23.0(18.0-31.0)$

and $15.0(8.0-15.0)$, respectively.

\section{Mechanical ventilation support and NIV failure}

Admission arterial blood gas analysis showed patients had hypercapnic respiratory failure. The median $\mathrm{pH}$ and arterial partial pressure of $\mathrm{CO}_{2}$ were $7.26(7.18-7.31)$ and 75.8 (62.7-85.1) $\mathrm{mmHg}$, respectively (Table 2). Twentytwo patients had invasive mechanical ventilation at the time of ICU admission, whereas 84 patients were first treated with NIV. During follow-up, NIV failure was observed in 38 patients with a median duration of $2.5(0.3-10.0)$ days. The statistically significant factors between NIV successful and failed patients are shown in Table 3. There was no difference for mechanical ventilation duration between both groups $(P=0.917)$. Hospital mortality was $65.8 \%$ in the NIV failed group whereas there were no deaths in the NIV successful group.

\section{Hemoglobin levels and presence of anemia}

The median hemoglobin level was 12.8 (11.6-15.0) $\mathrm{gm} / \mathrm{dL}$ in the whole study population. Only one patient had polycythemia (hemoglobin $>18.5 \mathrm{gm} / \mathrm{dL}$ ). Hemoglobin levels were negatively correlated with age $(r=-0.293$, $P=0.002$ ) and positively correlated with $\mathrm{FEV}_{1} \%$ predicted $(r=0.388, P=0.011)$ (Figure 2A and B). Anemia was present in half of the patients $(n=53)$ and there was no difference between sex groups $(49.4 \%$ [41/83] of male and $52.2 \%$ [12/23] of female patients were anemic; $P=1.00$ ). The median hemoglobin level in the anemic group was $11.6(10.2-12.3) \mathrm{gm} / \mathrm{dL}$ whereas it was $15.0(13.7-16.1)$ $\mathrm{gm} / \mathrm{dL}$ in the nonanemic group (Figure 3 ). Mean corpuscular volume did not differ between anemic and nonanemic patients (86.4 [79.9-91.4] and 88.7 [84.6-91.8] fL, respectively, $P=0.245)$. Anemic patients were older, had lower $\mathrm{FEV}_{1} \%$ predicted, and had higher APACHE II score (Table 4). NIV failure was observed more in the anemic 
Table I General characteristics of study population

\begin{tabular}{ll}
\hline $\mathrm{N}$ & 106 \\
Sex & \\
$\quad$ Male & $83(78.3)$ \\
Female & $23(21.7)$ \\
Age, years & $71.0(62.0-76.0)$ \\
Previous smoking history/active smoking & $59(55.7) / 25(23.6)$ \\
Pack-years & $60.0(60.0-96.3)$ \\
Pulmonary function tests ${ }^{a}$ & \\
FEV (liters) & $0.79(0.59-1.17)$ \\
FEV, \% predicted & $31.4(20.5-40.2)$ \\
Long-term oxygen therapy & $37(34.9)$ \\
Domiciliary NIV & $15(14.2)$ \\
Comorbidities & \\
- Hypertension & $60(56.6)$ \\
- Coronary artery disease & $35(33.0)$ \\
- Diabetes mellitus & $30(28.3)$ \\
- Arrhythmia & $22(20.8)$ \\
- Congestive heart failure & $21(19.8)$ \\
GCS score & $15.0(8.0-15.0)$ \\
APACHE II score & $23.0(18.0-31.0)$ \\
Respiratory arrest before ICU admission & $12(11.3)$ \\
Length of stay (days) between hospital & $1.0(0.0-5.0)$ \\
admission and ICU admission &
\end{tabular}

Notes: All values are expressed as numbers (percentages) or median (interquartile range). a Pulmonary function tests were available in 62 patients.

Abbreviations: APACHE, Acute Physiology and Chronic Health Evaluation; FEV forced expiratory volume in I second; GCS, Glasgow Coma Scale; ICU, intensive care unit; NIV, noninvasive ventilation.

Table 2 Clinical characteristics of study population

\begin{tabular}{|c|c|}
\hline \multicolumn{2}{|l|}{ Mechanical ventilation support } \\
\hline Invasive ventilation & $22(20.8)$ \\
\hline NIV & $84(79.2)$ \\
\hline NIV failure & $38(35.8)$ \\
\hline Duration of mechanical ventilation (days) & $7.0(3.0-18.0)$ \\
\hline \multicolumn{2}{|l|}{ Admission arterial blood gas values } \\
\hline $\mathrm{pH}$ & $7.26(7.18-7.31)$ \\
\hline $\mathrm{PaCO}_{2}(\mathrm{mmHg})$ & $75.8(62.7-85.1)$ \\
\hline $\mathrm{PaO}_{2}(\mathrm{mmHg})$ & $52.0(40.4-64.5)$ \\
\hline $\mathrm{PaO}_{2} / \mathrm{FiO}_{2}$ & $130.0(101.0-161.3)$ \\
\hline Lactate $(\mathrm{mmol} / \mathrm{L})$ & $1.6(1.1-2.5)$ \\
\hline White blood cell count $\left(\times 10^{3} / \mu \mathrm{L}\right)$ & $12.2(8.7-17.3)$ \\
\hline CRP (mg/L) & $8.9(3.5-13.5)$ \\
\hline Hemoglobin (gm/dL) & $12.8(11.6-15.0)$ \\
\hline Hematocrit (\%) & $40.8(35.9-48.7)$ \\
\hline $\operatorname{MCV}(f l)$ & $88.3(82.4-91.7)$ \\
\hline Anemia & $53(50)$ \\
\hline Polycythemia & $\mathrm{I}(0.9)$ \\
\hline ALB $(\mathrm{gm} / \mathrm{dL})$ & $3.3(2.9-3.6)$ \\
\hline ICU length of stay (days) & $\mid 3.0(7.8-2 \mid .0)$ \\
\hline Hospital length of stay (days) & $20.0(12.8-32.0)$ \\
\hline ICU mortality & $37(34.9)$ \\
\hline Hospital mortality & $39(36.8)$ \\
\hline
\end{tabular}

Note: All values are expressed as numbers (percentages) or median (interquartile range).

Abbreviations: ICU, intensive care unit; MCV, mean corpuscular volume; NIV, noninvasive ventilation; CRP, C-reactive protein; ALB, albumin.
Table 3 Statistically significant differences between noninvasive ventilation successful and failed patients $(n=84)$

\begin{tabular}{|c|c|c|c|}
\hline Variables & $\begin{array}{l}\text { NIV successful } \\
(n=46)\end{array}$ & $\begin{array}{l}\text { NIV failed } \\
(n=38)\end{array}$ & $P$-value \\
\hline APACHE II score & $18.0(15.8-22.0)$ & $27.5(20.0-32.8)$ & $<0.001$ \\
\hline GCS score & $15.0(\mid 5.0-15.0)$ & $12.0(5.5-15.0)$ & $<0.001$ \\
\hline Arrhythmia & $7(10.4)$ & $15(38.5)$ & $0.04 I$ \\
\hline Domiciliary NIV use & II (23.9) & $4(10.5)$ & 0.047 \\
\hline $\mathrm{CRP}(\mathrm{mg} / \mathrm{L})$ & $6.3(1.8-13.3)$ & $10.8(6-16.4)$ & 0.036 \\
\hline Hemoglobin (gm/dL) & $14.0(12.5-15.5)$ & $11.9(10.9-13.3)$ & $<0.001$ \\
\hline Hematocrit (\%) & $45.2(38.9-51.2)$ & $37.6(34.6-42.2)$ & 0.001 \\
\hline Anemia & $14(30.4)$ & $26(68.4)$ & 0.001 \\
\hline $\begin{array}{l}\text { Hospital length } \\
\text { of stay (days) }\end{array}$ & $15.0(9.5-22.0)$ & $23.5(18.0-38.0)$ & 0.001 \\
\hline Hospital mortality & $0(0.0)$ & $25(65.8)$ & $<0.001$ \\
\hline
\end{tabular}

Note: All values are expressed as numbers (percentages) or median (interquartile range).

Abbreviations: APACHE, Acute Physiology and Chronic Health Evaluation; GCS, Glasgow Coma Scale; NIV, noninvasive ventilation; CRP, C-reactive protein.

patients when compared to the nonanemic group ( $49 \%$ vs $22.6 \%$, respectively; $P=0.001$ ).

\section{Short-term mortality}

Thirty-nine patients (36.8\%) died during hospital stay (Table 5). When compared, nonsurvivors had higher APACHE II and lower GCS scores, had more domiciliary NIV use, and low serum ALB. Hospital mortality was $52.8 \%$ in the anemic group, whereas it was $20.8 \%$ in the nonanemic group $(P=0.001)$. Logistic regression analysis for hospital mortality (Table 6), showed presence of anemia and NIV failure were independent predictors of hospital death with ORs $(95 \% \mathrm{CI})$ of 3.99 ([1.39-11.40]; $P=0.010)$ and 2.56 ([1.60-4.09]; $P<0.001$ ), respectively. When hemoglobin levels (continuous variable) were used instead of anemia (categorical variable) in the regression model, OR for hospital mortality was 0.74 (0.59-0.94; $P=0.014)$.

\section{Long-term mortality}

Sixty-seven patients were discharged from hospital. Median follow-up time was 314 (47-773) days. During this period, 26 patients died. Overall mortality was $38.7 \%(n=41)$ for 28 days, $50.9 \%(\mathrm{n}=54)$ for 3 months, and $61.3 \%(\mathrm{n}=65)$ for 1 year. Hemoglobin levels did not differ between survivors and nonsurvivors $(P=0.903)$.

\section{Discussion}

Anemia of chronic disease is relatively common and an important factor in the natural history of COPD. In this study, the presence of anemia was associated with increased 

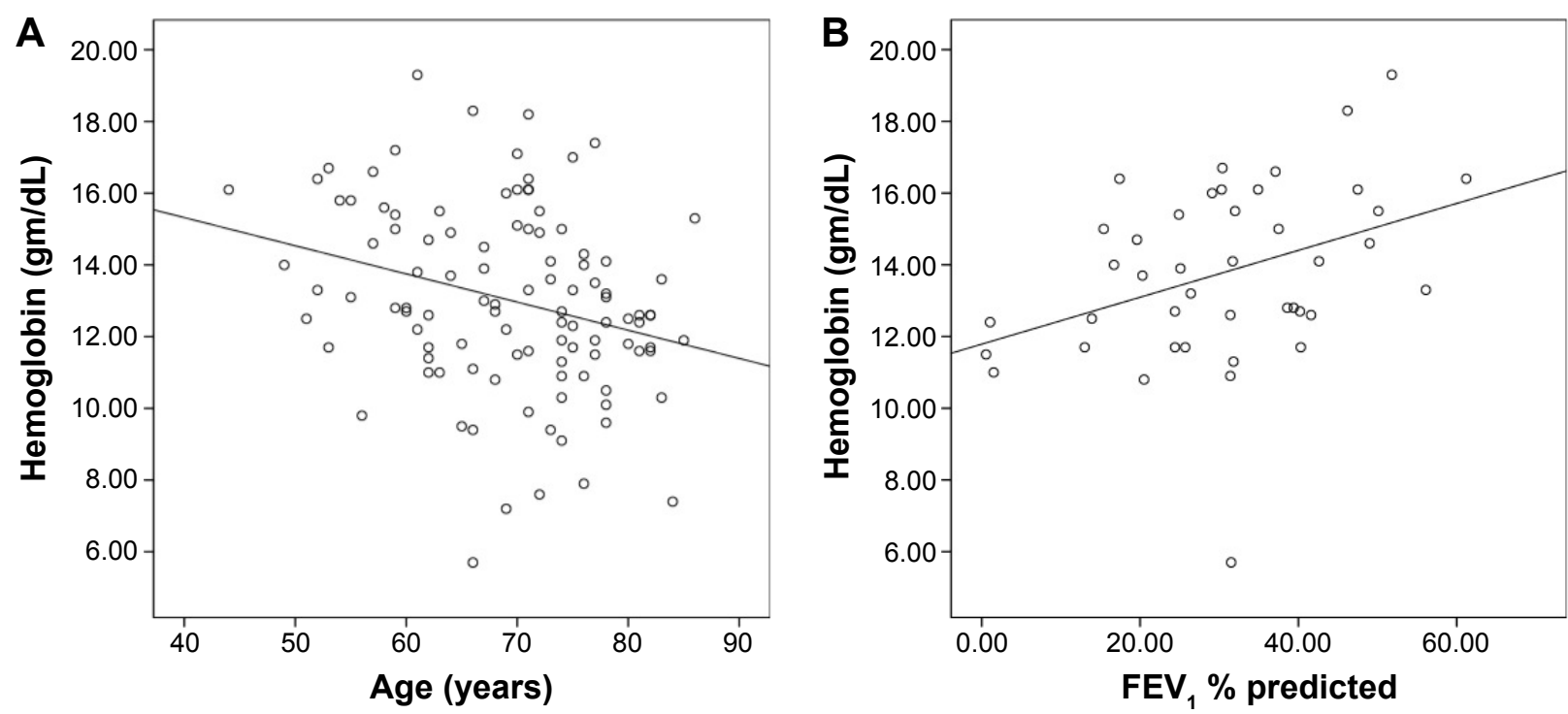

Figure 2 Correlations between hemoglobin concentration and age and FEV \% predicted.

Notes: (A) The correlation between hemoglobin and age (Spearman's correlation coefficient: $-0.293 ; P=0.002$ ). (B) The correlation between hemoglobin and FEV $\%$ \% predicted ( $n=62$; Spearman's correlation coefficient: $0.388 ; P=0.011$ ).

Abbreviation: $\mathrm{FEV}_{1}$, forced expiratory volume in I second.

hospital mortality in severe COPD exacerbations requiring mechanical ventilation support.

\section{Anemia as a comorbidity in COPD}

Anemia is a comorbidity of severe COPD and responsible for increased disease burden..$^{3-6}$ Anemic patients experience more dyspnea and have decreased functional capacity which in turn results in deterioration in the quality of life..$^{9-11}$ Additionally these patients exacerbate more and have higher risk of death than nonanemic patients. ${ }^{6,17,18}$ It is also reported to be an independent negative predictor of the duration of

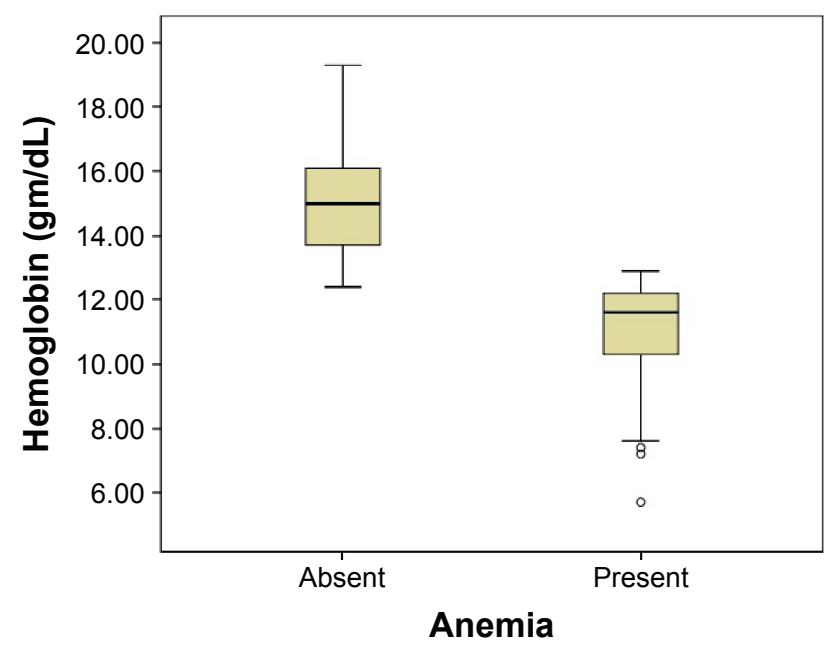

Figure 3 Hemoglobin levels in anemic and nonanemic patients. hospitalizations and survival of COPD patients receiving oxygen therapy. ${ }^{14}$

The prevalence of anemia is approximately $33 \%-44 \%$ in patients hospitalized for an exacerbation. ${ }^{7,8,19}$ In the present study, anemia was detected in $50 \%$ of patients with exacerbations. This result is relatively higher than previously reported, possibly because the study population comprised patients with more severe COPD. We have also found that hemoglobin levels were correlated with $\mathrm{FEV}_{1} \%$ predicted and anemic patients had lower $\mathrm{FEV}_{1}$ than nonanemic patients which is consistent with previously reported data. ${ }^{10,14}$

Table 4 Statistically significant differences between anemic and nonanemic patients

\begin{tabular}{llll}
\hline Variables & $\begin{array}{l}\text { Anemic } \\
\text { patients } \\
(\mathbf{n}=\mathbf{5 3})\end{array}$ & $\begin{array}{l}\text { Nonanemic } \\
\text { patients } \\
(\mathbf{n}=\mathbf{5 3})\end{array}$ & P-value \\
\hline Age (years) & $74.0(65.0-78.0)$ & $70(59.0-74.0)$ & 0.018 \\
FEV \% predicted & $25.7(13.5-35.2)$ & $32.0(25.0-46.9)$ & 0.042 \\
APACHE II score & $26.0(19.0-31.5)$ & $21.0(17.0-29.0)$ & 0.016 \\
Coronary artery disease & $23(43.4)$ & $12(22.6)$ & 0.038 \\
Arrhythmia & $17(32.1)$ & $5(9.4)$ & 0.007 \\
Hemoglobin (gm/dL) & $11.6(10.2-12.3)$ & $15.0(13.7-16.1)$ & $<0.001$ \\
NIV failure & $26(49.0)$ & $12(22.6)$ & 0.001 \\
Hospital length & $26.0(13.5-40.0)$ & $18.0(I I .5-24.5)$ & 0048 \\
of stay (days) & & & \\
Hospital mortality & $28(52.8)$ & $\mathrm{II}(20.8)$ & $0.00 \mathrm{I}$ \\
\hline
\end{tabular}

Notes: All values are expressed as numbers (percentages) or median (interquartile range). ${ }^{a}$ Available in 62 patients.

Abbreviations: APACHE, Acute Physiology and Chronic Health Evaluation; $\mathrm{FEV}_{\mathrm{I}}$, forced expiratory volume in I second; NIV, noninvasive ventilation. 
Table 5 Statistically significant factors related with hospital mortality

\begin{tabular}{|c|c|c|c|}
\hline Variables & $\begin{array}{l}\text { Survivors } \\
(n=67)\end{array}$ & $\begin{array}{l}\text { Nonsurvivors } \\
(\mathrm{n}=39)\end{array}$ & $P$-value \\
\hline APACHE II score & $20.0(17.0-28.0)$ & $28.0(22.0-34.0)$ & $<0.001$ \\
\hline GCS score & $15.0(12.0-15.0)$ & $10.0(5.0-10.0)$ & $<0.001$ \\
\hline Arrhythmia & $7(10.4)$ & $15(38.5)$ & 0.001 \\
\hline Domiciliary NIV use & $13(19.4)$ & $2(5.1)$ & 0.047 \\
\hline NIV failure & $13(19.4)$ & $25(64.1)$ & $<0.001$ \\
\hline CRP (mg/L) & $6.9(1.9-12.5)$ & II.0 (5.9-17.3) & 0.009 \\
\hline Hemoglobin (gm/dL) & $13.6(12.4-15.5)$ & $11.6(10.3-13.3)$ & $<0.001$ \\
\hline Hematocrit (\%) & $42.6(38.7-50.5)$ & $36.5(32.2-43.7)$ & $<0.001$ \\
\hline Anemia & $25(37.3)$ & $28(71.8)$ & 0.001 \\
\hline ALB $(\mathrm{gm} / \mathrm{dL})$ & $3.4(3.0-3.7)$ & $3.0(2.7-3.3)$ & 0.003 \\
\hline $\begin{array}{l}\text { Hospital length } \\
\text { of stay (days) }\end{array}$ & $17(12-25)$ & $26(16-39)$ & 0.030 \\
\hline
\end{tabular}

Note: All values are expressed as numbers (percentages) or median (interquartile range).

Abbreviations: APACHE, Acute Physiology and Chronic Health Evaluation; GCS, Glasgow Coma Scale; NIV, noninvasive ventilation; CRP, C-reactive protein; ALB, albumin.

\section{Anemia and short-term prognosis in severe COPD exacerbations}

Although the impact of anemia during stable phase of COPD was reported in many longitudinal cohort studies, the effect of anemia on clinical outcomes for COPD exacerbations, particularly in the ICU setting, was studied less. ${ }^{20-23}$ In this study, the presence of anemia is associated with an increased risk of death in severe COPD exacerbations with an OR of 3.99. We propose anemia should be considered as a risk stratification factor for severe COPD exacerbations in the ICU.

Anemia has been shown to be associated with increased mortality in COPD-related acute respiratory failure. ${ }^{8,20-23}$ Rasmussen et $\mathrm{al}^{22}$ evaluated COPD patients who needed invasive ventilation and found that $54.8 \%$ of anemic COPD patients died within 30 days with a mortality risk ratio of 3.1 (95\% CI 1.6-5.9). Another study reported that hemoglobin level was an independent predictor of hospital mortality

Table 6 Stepwise multivariate logistic regression analysis for independent predictors of hospital mortality

\begin{tabular}{llll}
\hline Variable & Odds ratio & 95\% confidence interval & $P$-value \\
\hline Age & 1.00 & $0.93-1.06$ & 0.874 \\
APACHE II score & 0.97 & $0.90-1.05$ & 0.470 \\
GCS score & 0.90 & $0.78-1.03$ & 0.123 \\
Arrhythmia & 2.80 & $0.89-8.87$ & 0.080 \\
Domiciliary NIV & 0.32 & $0.07-2.38$ & 0.323 \\
ALB & 0.47 & $0.18-1.29$ & 0.146 \\
NIV failure & 2.56 & $1.60-4.09$ & $<0.001$ \\
Anemia & 3.99 & $1.39-11.40$ & 0.010 \\
\hline
\end{tabular}

Abbreviations: APACHE, Acute Physiology and Chronic Health Evaluation; GCS, Glasgow Coma Scale; NIV, noninvasive ventilation; ALB, albumin.
(OR: $0.63,95 \%$ CI: $0.45-0.90 ; P=0.006){ }^{23}$ The impact of anemia on COPD exacerbations was also evaluated in the emergency room setting; a multicenter study performed in Canada showed anemia (hemoglobin $<10 \mathrm{gm} / \mathrm{dL}$ ) was the strongest predictor (OR 4.9; 95\% CI 2.1-11.7) of serious adverse events including death in patients admitted to the emergency room. ${ }^{24}$ All these data suggest that, besides being an important predictor of long-term survival, anemia should also be considered as a risk factor for short-term mortality in severe COPD exacerbations.

The mechanisms of the development of anemia in COPD are complex and outside the scope of this article, nevertheless disease severity seems to be one of the most important factors. ${ }^{25}$ Anemia was proposed as a marker for end-stage COPD.${ }^{22} \mathrm{COPD}$ is a systemic inflammatory disease in which many cytokines, including IL-1, IL-6, and TNF-alpha, play a role. These cytokines are also involved in inhibition of erythropoiesis at different steps of the erythropoietic pathway. In the presence of severe systemic inflammation, impairment of erythropoiesis becomes evident as anemia of chronic inflammation. ${ }^{5,25}$ In addition to chronic changes in the erythropoiesis, acute changes in hemoglobin levels were also reported during exacerbations. Markoulaki et $\mathrm{al}^{26}$ showed that a severe exacerbation itself caused transient changes in hemoglobin levels with a median decrease of $1.3 \mathrm{gm} / \mathrm{dL}$. There was a negative correlation between hemoglobin and erythropoietin (EPO) levels which points out increased EPO resistance during exacerbations. It is already known that EPO resistance is directly correlated with the levels of inflammatory cytokines and therefore the level of systemic inflammation. Repeated exacerbations could further inhibit erythropoiesis, and as a result a significant decrease in hemoglobin levels can occur in severe COPD. Thus, anemia could be accepted as a surrogate of severe systemic inflammation and might be helpful in identifying sicker patients.

Additionally, another important mechanism responsible for the development of anemia of chronic disease is the alteration in iron metabolism. ${ }^{5,7,27}$ Increased levels of inflammatory cytokines and hepcidin, a peptide hormone that regulates iron homeostasis, also play a significant role in impaired iron utilization which causes functional iron deficiency. It has been shown that functional iron deficiency, even before the onset of anemia, is related to hypoxemia, more frequent selfreported exacerbations, decreased exercise tolerance, and limited response to pulmonary rehabilitation. ${ }^{27,28}$ Recently, it was suggested that specific attention should be paid to iron deficiency even in the absence of anemia, and iron supplementation may be helpful in anemic COPD patients. ${ }^{29}$ 
Researches performed in other chronic inflammatory diseases and one study done in COPD with renal impairment have shown improvement in patient outcomes with iron replacement. ${ }^{7,30}$ However, more data are needed to understand the importance of functional iron deficiency in COPD and the beneficial effect of iron replacement needs to be confirmed with randomized controlled trials.

On the other hand, COPD patients might be more sensitive to anemia than we think. This hypothesis is supported by the data from two previous studies. COPD patients were reported to have higher a mortality rate during gastrointestinal bleeding when compared to non-COPD patients. ${ }^{31}$ In the second study, low hematocrit levels were associated with worse outcomes in COPD patients after elective open abdominal aortic aneurysmectomy. ${ }^{32}$ The reason for this negative effect of anemia on outcomes is still unknown. However, from the physiological point of view, anemia causes a decrease in oxygen transport capacity of blood which could impair physiological and clinical parameters in COPD. ${ }^{4}$ Yuruk et al showed that low hemoglobin levels were associated with impaired tissue oxygen saturation in the microcirculation, and hemoglobin correction resulted in improvement in oxygen carrying capacity and tissue oxygen saturation. ${ }^{33,34}$ The negative effect of low hemoglobin levels on tissue oxygenation might be clinically important in severe COPD, especially during exacerbations.

The current study also showed NIV failure is more common in anemic COPD patients. Haja Mydin et a ${ }^{8}$ looked for prognostic factors in hypercapnic respiratory failure and showed that anemia was related to increased risk of NIV failure. A COPD database study $(n=132,424)$ showed anemic patients had not only more ICU admissions but also needed more ventilatory support. ${ }^{35}$ Anemia was also reported as a risk factor for extubation and weaning failure. ${ }^{36,37}$ Depending on its severity, anemia is associated with increased work of breathing and reduced exercise tolerance in COPD. ${ }^{4,9,11}$ It has been shown that the relationship between muscle oxygenation and peak oxygen consumption varies widely in COPD, and oxygen consumption is highly influenced by blood oxygenation and oxygen utilization level., ${ }^{4,38}$ Anemic COPD patients also exhibit decreased diffusing capacity corrected for hemoglobin. ${ }^{19}$ All these changes in oxygen transport lead to decrease in aerobic capacity and therefore skeletal muscle dysfunction in severe COPD during exercise. One can expect these changes to be more evident in patients with low hemoglobin levels, especially during exacerbations because of increased oxygen demand due to increased work of breathing and impaired cardiopulmonary interactions. A case series study done by Schönhofer et al ${ }^{39}$ showed transfusion decreases minute ventilation and work of breathing in anemic COPD patients. The same group also showed that transfusion helped successful weaning from ventilator in five patients. ${ }^{40}$ However, the relationship between anemia and ventilation is complex and more data are needed to understand the consequences of anemia on gas exchange and transport during "pump failure" in COPD.

The optimum threshold for hemoglobin in COPD patients is still being debated. Usually a hemoglobin level of $>10 \mathrm{gm} / \mathrm{dL}$ is considered as a "safe" zone, however this may not be true for COPD patients. The ANTADIR study showed every $5 \%$ increase in hematocrit level was associated a relative risk of $0.86(0.83-0.89)$ for 3-year mortality. ${ }^{14}$ Kollert et a ${ }^{13}$ proposed hemoglobin values greater than $14.3 \mathrm{gm} / \mathrm{dL}$ for females and $15.1 \mathrm{gm} / \mathrm{dL}$ for males, which are much higher than WHO's definition, were associated with better outcomes in patients with chronic respiratory failure. Although hemoglobin levels between 7-9 gm/dL are considered as tolerated well in the ICU setting, Rasmussen et al ${ }^{22}$ reported a cutoff value of hemoglobin level $<12 \mathrm{gm} / \mathrm{dL}$ was related to increased risk of death in intubated COPD patients. Interestingly, Stiell et a ${ }^{24}$ showed that patients with exacerbations who ended up with a serious adverse event (including ICU admission, need for mechanical ventilation, and death within 30 days) had hemoglobin levels of $12.3 \mathrm{gm} / \mathrm{dL}$ which could be considered as normal. In regard to these findings, the "safe" hemoglobin level for COPD is probably higher than our standard anemia definitions.

\section{Anemia and long-term prognosis in severe COPD exacerbations}

Studies done in COPD with chronic respiratory failure have shown the presence of anemia was associated with worse long-term survival, however, we were not able to show such an effect in our cohort. ${ }^{13,14,18}$ It should be kept in mind that the current study was designed and powered for the primary outcome (hospital mortality). Another important point to consider is study subjects had acute respiratory failure and only one third of the patients had chronic respiratory failure and were using oxygen at home. Finally, the follow-up period might have been too short to see a difference. When compared to previous reports, our median follow-up time was relatively shorter (36 vs 10.5 months, respectively). ${ }^{13}$

\section{Limitations and strengths of the study}

This study has several important limitations. First, it is a single-center study and the results may not be generalizable 
to other centers. Second, all patients did not have recent PFTs; therefore, we were unable to assess disease severity according to the GOLD classification system in the whole cohort. Third, mortality in the critically ill patients may potentially have been influenced by many confounding factors. Although we have attempted to include a wide range of all possible confounders in the mortality analysis, there is still a lack of data on therapy and complications during ICU stay. Another important point to consider is the etiology of anemia, including data for previous exacerbations and hospitalizations, was not evaluated in this study.

Besides these limitations, the present study has some important strengths. There is limited data about the impact of anemia on severe COPD exacerbations requiring mechanical ventilatory support. Most of the studies done in the ICU setting included not only patients with exacerbations but also patients with other diagnoses such as pneumonia and cardiogenic pulmonary edema. ${ }^{20-23} \mathrm{We}$ were meticulous to include only patients with exacerbations. Moreover, the study cohort consisted of patients with different degrees of acute respiratory failure treated with both NIV and invasive ventilation; therefore, our results might apply to a greater percentage of patients for prediction of prognosis. Finally, comorbidities such as congestive heart failure are known to have an increased risk of death in the presence of anemia. For this reason, instead of using a comorbidity index, each comorbidity was assessed separately in order to understand its own relationship with anemia and mortality.

\section{Conclusion}

This study highlights two important results: first, anemia is related with increased risk of death in acute respiratory failure due to severe COPD exacerbations. Second, anemia is associated with NIV failure. Further studies are needed to understand the physiological consequences of anemia in COPD exacerbations and its impact on clinical outcomes. Whether correction of anemia has beneficial effects in COPD is another challenging research question waiting to be answered.

\section{Acknowledgments}

The authors would like to thank Gül Ergör and William Vollmer for their valuable comments and contributions to statistical analysis. We also thank American Thoracic Society and Sonia Buist for Methods in Epidemiologic Clinical and Operations Research (MECOR) program for their encouragement and continuous education for research. This study was presented as an oral presentation at the European Respiratory Society Annual Congress 2015, Amsterdam, Holland.

\section{Disclosure}

The authors report no conflicts of interest in this work.

\section{References}

1. Global Initiative for Chronic Obstructive Lung Disease (GOLD) [homepage on the Internet]. Global strategy for the diagnosis, management and prevention of chronic obstructive pulmonary disease [updated 2015]. Available from: www.goldcopd.org. Accessed June 16, 2016.

2. Chatila WM, Thomashow BM, Minai OA, Criner GJ, Make BJ. Comorbidities in chronic obstructive pulmonary disease. Proc Am Thorac Soc. 2008;5(4):549-555.

3. Cavailles A, Brinchault-Rabin G, Dixmier A, et al. Comorbidities in COPD. Eur Respir Rev. 2013;22(130):454-475.

4. Similowski T, Agusti A, MacNee W, Schönhofer B. The potential impact of anaemia of chronic disease in COPD. Eur Respir J. 2006;27(2): 390-396.

5. Yohannes AM, Ershler WB. Anemia in COPD: A systematic review of the prevalence, quality of life, and mortality. Respir Care. 2011;56(5): 644-652.

6. Martinez-Rivera C, Portillo K, Munoz-Ferrer A, et al. Anemia is a mortality predictor in hospitalized patients for COPD exacerbation. COPD. 2012;9(3):243-250.

7. Silverberg DS, Mor R, Weu MT, Schwartz D, Schwartz IF, Chernin G. Anemia and iron deficiency in COPD patients: prevalence and the effects of correction of the anemia with erythropoiesis stimulating agents and intravenous iron. BMC Pulm Med. 2014;14:24.

8. Haja Mydin H, Murphy S, Clague H, Sridharan K, Taylor IK. Anemia and performance status as prognostic markers in acute hypercapnic respiratory failure due to chronic obstructive pulmonary disease. Int J Chron Obstruct Pulmon Dis. 2013;8:151-157.

9. Cote C, Zilberberg MD, Mody SH, Dordelly LJ, Celli B. Haemoglobin level and its clinical impact in a cohort of patients with COPD. Eur Respir J. 2007;29(9):923-929.

10. Ferrari M, Manea L, Anton K, et al. Anemia and hemoglobin serum levels are associated with exercise capacity and quality of life in chronic obstructive pulmonary disease. BMC Pulm Med. 2015;15:58.

11. Boutou AK, Stanopoulos I, Pitsiou GG, et al. Anemia of chronic disease in chronic obstructive pulmonary disease: a case control study of cardiopulmonary exercise responses. Respiration. 2011;82(3):237-245.

12. Boutou AK, Pitsiou GG, Stanopoulos I, Kontakiotis T, Kyriazis G, Argyropoulou P. Levels of inflammatory mediators in chronic obstructive pulmonary disease patients with anemia of chronic disease: A casecontrol study. QJM. 2012;105(7):657-663.

13. Kollert F, Tippelt A, Müller C, et al. Hemoglobin levels above anemia thresholds are maximally predictive for long term survival in COPD with chronic respiratory failure. Respir Care. 2013;58(7): 1204-1212.

14. Chambellan A, Chailleux E, Similowski T; ANTADIR Observatory Group. Prognostic value of the hematocrit in patients with severe COPD receiving long-term oxygen therapy. Chest. 2005;128(3):1201-1208.

15. World Health Organization. Haemoglobin concentrations for the diagnosis of anaemia and assessment of severity. Vitamin and Mineral Nutrition Information System. Geneva: World Health Organization; 2011. Available from: http://www.who.int/vmnis/indicators/haemoglobin.pdf. Accessed June 4, 2016.

16. Dean AG, Sullivan KM, Soe MM. OpenEpi: Open Source Epidemiologic Statistics for Public Health, Version [updated May 4, 2015]. Available from: www.OpenEpi.com. Accessed June 16, 2016.

17. Ozyılmaz E, Kokturk N, Teksut G, Tatlicioglu T. Unsuspected risk factors of frequent exacerbations requiring hospital admission in chronic obstructive pulmonary disease. Int J Clin Pract. 2013;67(7): 691-697. 
18. Boutou AK, Karrar S, Hopkinson NS, Polkey MI. Anemia and survival in chronic obstructive pulmonary disease: a dichotomous rather than continuous variable. Respiration. 2013;85(2):126-131.

19. Guo J, Zheng C, Xiao Q, et al. Impact of anaemia on lung functions and exercise capacity in patient with severe chronic obstructive pulmonary disease. BMJ Open. 2015;5(10):e008295.

20. Asmundsson T, Kilburn KH. Survival of acute respiratory failure. 145 patients observed 5 to 8 and one-half years. Ann Intern Med. 1974;80(1): 54-57.

21. Nevins ML, Epstein SK. Predictors of outcome for patients with COPD requiring invasive mechanical ventilation. Chest. 2001;119(6): 1840-1849.

22. Rasmussen L, Christensen S, Lenler-Petersen P, Johnsen SP. Anemia and 90-day mortality in COPD patients requiring invasive mechanical ventilation. Clin Epidemiol. 2010;3:1-5.

23. Ucgun I, Metintas M, Moral H, Alatas F, Yildirim H, Erginel S. Predictors of hospital outcome and intubation in COPD patients admitted to the respiratory ICU for acute hypercapnic respiratory failure. Respir Med. 2006;100(1):66-74.

24. Stiell IG, Clement CM, Aaron SD, et al. Clinical characteristics associated with adverse events in patients with exacerbation of chronic obstructive pulmonary disease: a prospective cohort study. CMAJ. 2014; 186(6):E193-E204.

25. Portillo K, Martinez Rivera C, Ruiz-Manzano J. Anaemia in chronic obstructive pulmonary disease. Does it really matter? Int J Clin Pract. 2013;67(6):558-565.

26. Markoulaki D, Kostikas K, Papatheodorou G, et al. Hemoglobin, erythropoietin and systemic inflammation in exacerbations of chronic obstructive pulmonary disease. Eur J Intern Med. 2011;22(1):103-107.

27. Nickol AH, Frise MC, Cheng HY, et al. A cross-sectional study of the prevalence and associations of iron deficiency in a cohort of patients with chronic obstructive pulmonary disease. BMJOpen. 2015; 5(7):e007911.

28. Barberan-Garcia A, Rodriguez DA, Blanco I, et al. Non-anaemic iron deficiency impairs response to pulmonary rehabilitation in COPD. Respirology. 2015;20(7):1089-1095.

29. Vasquez A, Logomarsino JV. Anemia in chronic obstructive pulmonary disease and the potential role of iron deficiency. COPD. 2016;13(1): 100-109.
30. Avni T, Leibovici LL, Gafter-Gvilli A. Iron supplementation for the treatment of chronic heart failure and iron deficiency: systematic review and meta-analysis. Eur J Heart Fail. 2012;14(4):423-429.

31. Cappell MS, Nadler SC. Increased mortality of acute upper gastrointestinal bleeding in patients with chronic obstructive pulmonary disease. A case controlled multiyear study of 53 consecutive patients. Dig Dis Sci. 1995;40(2):256-262.

32. Upchurch GR Jr, Proctor MC, Henke PK, et al. Predictors of severe morbidity and death after elective abdominal aortic aneurysmectomy in patients with chronic obstructive pulmonary disease. J Vasc Surg. 2003; 37(3):594-599.

33. Yuruk K, Bartels SA, Milstein DM, Bezemer R, Biemond BJ, Ince C. Red blood cell transfusions and tissue oxygenation in anemic hematology outpatients. Transfusion. 2012;52(3):641-646.

34. Yürük K, Almac E, Bezemer R, Goedhart P, de Mol B, Ince C. Blood transfusions recruit the microcirculation during cardiac surgery. Transfusion. 2011;51(5):961-967.

35. Halpern MT, Zilberberg MD, Schmier JK, Lau EC, Shorr AF. Anemia, costs and mortality in chronic obstructive pulmonary disease. Cost Eff Resour Alloc. 2006;4:17.

36. Khamiees M, Raju P, DeGirolamo A, Amoateng-Adjepong Y, Manthous CA. Predictors of extubation outcome in patients who have successfully completed a spontaneous breathing trial. Chest. 2001;120(4): $1262-1270$.

37. Lai YC, Ruan SY, Huang CT, Kuo PH, Yu CJ. Hemoglobin levels and weaning outcome of mechanical ventilation in difficult to wean patients: A retrospective cohort study. PLoS One. 2013;8(8):e73743.

38. Tabira K, Horie J, Fujii H, et al. The relationship between skeletal muscle oxygenation and systemic oxygen uptake during exercise in subjects with COPD: a preliminary study. Respir Care. 2012;57(1): 1602-1610.

39. Schönhofer B, Wenzel M, Geibel M, Köhler D. Blood transfusion and lung function in chronically anemic patients with severe chronic obstructive pulmonary disease. Crit Care Med. 1998;26(11):1824-1828.

40. Schönhofer B, Böhrer H, Köhler D. Blood transfusion facilitating difficult weaning from the ventilator. Anaesthesia. 1998;53(2):181-184.
International Journal of COPD

\section{Publish your work in this journal}

The International Journal of COPD is an international, peer-reviewed journal of therapeutics and pharmacology focusing on concise rapid reporting of clinical studies and reviews in COPD. Special focus is given to the pathophysiological processes underlying the disease, intervention programs, patient focused education, and self management protocols.

\section{Dovepress}

This journal is indexed on PubMed Central, MedLine and CAS. The manuscript management system is completely online and includes a very quick and fair peer-review system, which is all easy to use. Visit http://www.dovepress.com/testimonials.php to read real quotes from published authors. 